\title{
HERMÈS: EXPRESSÕES DA MARCA E RITUAIS DE CONSUMO
}

\section{Hermès: brand expressions and consumption rituals}

\section{Hermès: espressiones de la marca y rituales de consumo}

\author{
Flavia Igliori Gonsales ${ }^{1}$ \\ Diogo Kawano ${ }^{2}$ \\ Janiene Santos ${ }^{3}$
}

\section{Resumo}

O presente artigo apresenta a análise das expressividades da marca de luxo Hermès, a partir de método semiótico baseado na Teoria Geral dos Signos, de Charles Peirce e no modelo de transferência de significados no mundo culturalmente constituído para os bens de consumo, proposto por McCracken (2003). Verificou-se que os signos da marca são condizentes às estratégias da Hermès, cujo consumo gera efeitos de sentidos que fortalecem os vínculos com seus públicos.

Palavras-chave: marca de luxo, consumo, Cultura, semiótica.

\footnotetext{
Abstract

In this paper, we analyze the expressions of the luxury brand Hermès, through a semiotic method based on the Theory of Signs, from Charles Peirce, and on the transfer model of meaning in the world of consumer goods, proposed by McCracken (2003). After the analysis, we conclude that Hermès brand expressions are consistent and integrated with the brand

${ }^{1}$ Flavia Igliori Gonsales. Graduada e mestre em Arquitetura e Urbanismo pela FAU-USP. Especialista em Gestão de Projetos Culturais pelo Centro de Estudos Latino-Americanos sobre Cultura e Comunicação, da ECA-USP. Email: flagonsales@gmail.com

${ }^{2}$ Diogo Kawano. Mestrando em Ciências da Comunicação pela Escola de Comunicações e Artes da Universidade de São Paulo (ECA-USP). E-mail: drkawano@gmail.com.

3 Janiene Santos. Doutoranda e Mestre em Ciências da Comunicação pela Escola de Comunicações e Artes da Universidade de São Paulo (ECA-USP). Especialista em Gestão do Design pelo Centro Universitário Belas Artes de São Paulo. Email: janienesantos@usp.br_ou janiene@uol.com.br.
} 
Hermès: expressões da marca e rituais de consumo

de Flávia Igliori Gonsales, Diogo Kawano e Janiene Santos

strategy, strengthening its bonds with stakeholders, who are seeking to appropriate the generated meaning effects through identitary consumption of Hermès.

Keywords: luxury brand, consumption, culture, semiotic.

\section{Resumen}

En este trabajo, se analizan las expresiones de la marca de lujo Hermès, a través de un método semiótico basado en la Teoría de los Signos, de Charles Peirce, y en el modelo de transferencia de significado en el mundo de los bienes de consumo, propuesto por McCracken (2003). Tras el análisis, se concluye que las expresiones marcarias son coherentes e integradas con la estrategia de marca, lo que fortalece los lazos con su publico, que busca apropiarse de los efectos de sentido generados a través del consumo identitario de la marca Hermès.

Palabras-clave: marca de lujo, consumo, cultura, semiótica.

\section{INTRODUÇÃO}

Em meio à atual crise financeira global, quando muitas empresas enfrentam quedas nos lucros e outras quebram, a marca francesa Hermès vem aumentando suas vendas a cada ano e foi avaliada pela quinta vez consecutiva como a segunda marca mais valiosa do segmento de luxo, conforme o ranking global BrandZ, da Millward Brown (2012).

Ao longo das últimas décadas, o conceito e a gestão de marcas evoluíram. Antes com um enfoque extremamente visual e tangível, nas funções de identificação e diferenciação, atualmente o branding passou a considerar a imaterialidade das marcas e os aspectos de construção de vínculos afetivos (Perez \& Bairon, 2009: 1). Os especialistas acadêmicos e de mercado afirmam que as marcas devem proporcionar experiências sensoriais e emocionais memoráveis para encantarem e conquistarem seus públicos e assim tornarem-se mais fortes e valiosas. (SCHMITT \& SIMONSON, 2002; PEREZ, 2004; GOBÉ, 2009; LINSDTORM, 2005; JENKINS, 2009, entre outros).

O conceito de consumo, incluindo o de luxo, também evoluiu. Estigmatizado como vilão por vários intelectuais desde os anos 1950 e 1960 por nos levar à superficialidade, egoísmo, alienação e prisão da personalidade, segundo McCracken (2012), hoje alguns estudiosos já consideram o consumir muito além de um ato simplesmente ostentatório, mas como prática cultural e mecanismo identitário, de comunicação e satisfação de necessidades além das 
biológicas, mas também psicológicas, para os sujeitos que vivem a sociedade hipermoderna, (MCCRACKEN, 2003, 2012; LIPOVETSKY \& ROUX, 2005; CASTARÈADE, 2005).

Este artigo busca investigar as expressões marcárias da Hermès, com o objetivo de verificar como acontecem essas construções de efeitos de sentido e compreender como é possível se alinhar tradição com jovialidade e inovação, entre outros méritos das narrativas dessa marca de sucesso. Nesse sentido, as considerações prático-teóricas a respeito da semiótica peirceana, bem como os apontamentos sobre cultura, consumo e transferência de significado trazidos por McCracken (2003), serão bastante profícuos para um melhor entendimento deste trabalho, como se verá mais detalhadamente na explanação metodológica a seguir.

\section{MÉTODO DE ANÁLISE}

O roteiro analítico terá como base a Teoria Geral dos Signos de Charles Peirce adaptada à comunicação mercadológica, em um modelo desenvolvido por Lucia Santaella $(2003,2000)$ e Clotilde Perez (2004). A análise das expressões marcárias será, deste modo, realizada em três dimensões (ver quadro 1): a dimensão qualitativo-icônica (primeiridade), a singular-indicial (secundidade) e a convencional-simbólica (terceiridade).

Quadro 1 - Relações triádicas do signo

\begin{tabular}{|c|c|c|}
\hline \multirow{2}{*}{ NELE MESMO } & SIGNO & $\begin{array}{c}\text { EM RELAÇAO AOS } \\
\text { EFEITOS GERADOS }\end{array}$ \\
\hline Quali-signos & EM RELAÇÃO AO OBJETO & Emocionais \\
\hline Sin-signos & ícones & Funcionais \\
\hline Legi-signos & índices & Lógicos \\
\hline
\end{tabular}

Fonte: desenvolvido pelos autores

O objeto de análise deste artigo são as expressões da marca Hermès, especificamente o nome e o logotipo (do mix de identidade) e a propaganda impressa (do mix de marketing) criada para a coleção outono/inverno de 2012. Deste modo, será seguido o modelo descritivo de marca concebido Paulo de Lencastre e Ana Côrte-Real (2007), baseado em três pilares fundamentais:

- O pilar da identidade (identity mix): o sinal ou conjunto de sinais de identidade da marca;

- O pilar do objeto (marketing mix), que engloba as diferentes ofertas da marca, bem como a organização e ações de marketing que as suportam; 
- O pilar do mercado (response mix): os públicos-alvo e suas diferentes respostas à marca.

Ademais, de forma complementar aos aspectos da semiótica acima mencionados, foi realizada também uma abordagem acerca dos rituais de consumo presentes em McCracken (2003). Tais rituais ajudam a compreender como os efeitos de sentido possíveis se dão à luz de um determinado contexto cultural e das distintas maneiras que o indivíduo tem de transferir os significados dos bens para si próprios.

\section{SOBRE A MARCA HERMÈS}

A marca Hermès, originalmente uma selaria, foi fundada em 1837, por Thierry Hermès, na cidade de Paris. Segundo o site da empresa, a oficina fabricava e vendia rédeas e arreios. Em 1880, instalou-se no número 25 da rue Faubourg Saint-Honoré, quando o filho de Thierry assumiu os negócios, cuja clientela era formada pela aristocracia francesa.

Com a virada do século XX, a invenção e popularização do automóvel, a Hermès passou por seu primeiro "reposicionamento", ao adaptar a técnica do pesponto no couro para as linhas de bagagens, bolsas e carteiras, em 1918. Desde então, os lançamentos importantes para a grife foram, segundo matéria de Cláudia Jordão para a revista Isto É (2009): a criação de bolsas com zíper, em 1923; a primeira coleção de roupas femininas, desenhada por Émile-Maurice (neto do fundador), em 1929; o primeiro lenço de seda ("carrê") inspirado nos modelos usados pelos cavaleiros, em 1937, hoje um emblema da marca. A primeira bolsa da grife foi lançada em 1935 e tornou-se famosa ao ser usada pela princesa de Mônaco, Grace Kelly, duas décadas depois batizada de "Kelly". O modelo mais desejado e emblemático atualmente é a bolsa "Birkin", inspirada por e co-criada com a cantora inglesa Jane Birkin, em 1984.

Em outubro de 2010, a LVMH (maior holding de marcas de luxo do mundo, dona da Louis Vuitton), comprou 17\% das ações da Hermès, participação que cresceu para quase 22\% em meados de 2011. Para se defenderem do avanço do conglomerado, membros da família Hermès criaram a holding H51, que hoje detém 50,2\% da companhia, segundo a revista Exame (2011). Em entrevista para o periódico americano The Wall Street Journal (2011), o então CEO da empresa, Patrick Thomas, declarou que a Hermès é formada por "artesãos e criativos": "nosso combate com a LVMH não é uma luta econômica, é uma luta cultural. Nós tentamos fazer poesia e temos excelentes resultados econômicos. Devemos proteger isso". 
Avaliada novamente como a segunda marca global mais valiosa do luxo (U\$19,1 bilhões) no ranking da Millward Brown (2012), perdendo apenas para a LVMH, o momento atual da marca é um perfeito exemplo do que Lipovetsky descreveu, originalmente em 2003, sobre os novos rumos do luxo, no qual as tradicionais lutas de concorrência pelo prestígio ficam menores em relação às disputas pela concentração de mercado, em operações de fusão e de aquisição, visando a formação de impérios industriais internacionais (LIPOVETSKY \& ROUX, 2005). Em conformidade, Roux explica o processo como uma "verdadeira mutação" do setor de luxo, que passou "de uma lógica artesanal e familiar a uma lógica industrial e financeira" (Ibid.: 90). Mutação à qual a Hermès parece buscar sua própria maneira de adaptação, sem perder sua essência e seu valor.

\section{ANÁLISE SEMIÓTICA DE ELEMENTOS DO IDENTITY MIX}

O pilar da identidade, segundo modelo de Lencastre e Côrte-Real (2007), é distinguido em três níveis: a identidade central (core identity), que se trata do nome da marca; a identidade efetiva/tangível (actual identity), as expressões gráficas registradas da identidade central; e a identidade ampliada (augmented identity), que inclui todos os outros sinais de marca protegidos juridicamente, como o slogan, uma garrafa diferenciada, um mascote, etc. Para fins de aprofundamento, a análise irá se restringir aos elementos primeiros da identidade verbal e da identidade visual, ou seja, o nome (identidade central) e o logotipo (identidade efetiva).

\subsection{Identidade central: o nome}

Seguindo a tipologia empírica de sete tipos básicos de nome, criada por Perez (2004), pode-se afirmar que a marca estudada tem nome de tipo patronímico, pois remete ao sobrenome do criador e fundador, em forma mista com o tipo simbólico, uma vez que faz alusão ao deus grego Hermes, filho de Zeus e de Maia (Mercúrio, na mitologia romana). Muitos poderes e significados foram atribuídos a ele: o mensageiro dos deuses, o comunicador, o deus condutor da alma dos mortos ao mundo inferior, o deus alquimista, da transmutação, das estradas e viagens, das possibilidades, entre outros (CIRLOT, 1971). 
No quadro a seguir, apresentamos a análise semiótica do nome da marca Hermès nas três dimensões ou níveis, por meio da qual foi possível inferir os efeitos de sentido potenciais (palavras em negrito) nas mentes que o interpretam:

Quadro 2 - Análise semiótica do nome Hermès

\begin{tabular}{|l|l|}
\hline Qualitativo-icônico & Leveza, movimento (êeerrrrrr), continuidade (êeeessss); \\
\hline Singular-indicial & $\begin{array}{l}\text { Indica pistas da origem francesa (pela pronúncia), indica origem } \\
\text { mitológica, algo divino, poderoso, mágico, sobrenatural; }\end{array}$ \\
\hline $\begin{array}{l}\text { Convencional- } \\
\text { simbólico }\end{array}$ & $\begin{array}{l}\text { Representa a sofisticação e elegância francesas, a moda; } \\
\text { Evoca os poderes mágicos e a imortalidade/perenidade } \\
\text { dos deuses do Olimpo. }\end{array}$ \\
\hline
\end{tabular}

Fonte: desenvolvido pelos autores

\subsection{Identidade tangível: o logotipo}

O logotipo, graças à sua capacidade expressiva e de síntese visual, tem sua importância confirmada unanimemente na literatura de branding (gestão de marca). Ele é visto como o "elemento básico para uma identidade visual consistente" (ALLEN \& SIMMONS, 2004: 118), o resumo visual da marca (MILETSKY \& SMITH, 2009), e "o mais importante ativo visual de uma companhia" (GOBÉ, 2009: 126). Lencastre e Côrte-Real (2010: 7) especificam três componentes do logotipo: o lettering (componente tipográfico); o drawing (componente simbólico desenhado); e o coloring (código cromático).

\subsubsection{O componente tipográfico}

Conforme Perez (2004: 53), "o modo como desenhamos as letras é responsável pelas conotações emocionais que queremos gerar, especialmente quando tratamos de logotipos". Segundo Rogener, Pool e Packhauser (1995: 14), as diversas formas tipográficas (peso, curvas, serifas) trazem "informações codificadas, independentemente do conteúdo da mensagem do texto em si", informações acessadas subconscientemente, antes mesmo da leitura de qualquer letra.

Observando o logotipo da marca (ver Figura 1A), verificamos que parte tipográfica principal (HERMÈS) é composta por letras em caixa alta, de serifa quadrada (tipo egípcia ou 
egipciana), em peso médium-bold. A parte secundária (PARIS) é composta por letras em caixa alta, sem serifa, em peso regular-light.

Fig. 1A e 1B - O logotipo Hermès e a obra "Le Duc Attelé", de Alfred de Dreux.
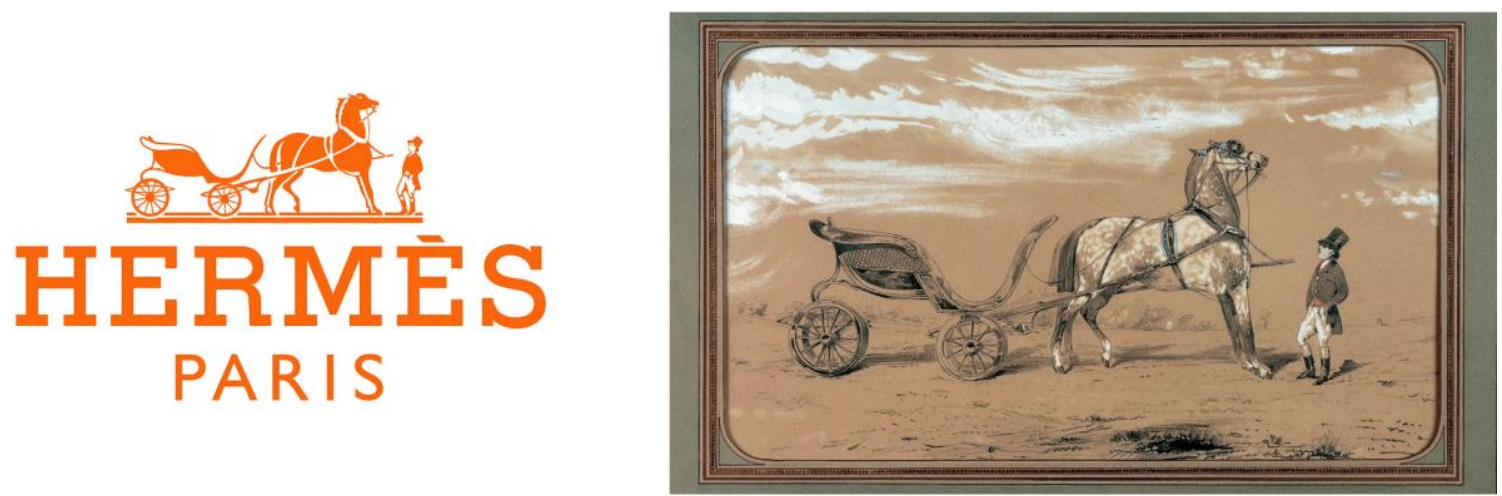

Fonte: site da empresa (1a: redesenho sobre logotipo oficial.

1b: framing do vídeo "Emile Hermès Collection - Duc attelé, groom à l'attente")

Feita a descrição formal, segue a análise:

Quadro 3 - Análise semiótica do componente tipográfico do logotipo Hermès

\begin{tabular}{|l|l|}
\hline Qualitativo-icônico & $\begin{array}{l}\text { Imponência, força, masculinidade (caixa alta, serifas); } \\
\text { Leveza, feminilidade (sem serifa, kerning aberto); } \\
\text { Equilíbrio (simetria no eixo vertical); }\end{array}$ \\
\hline Singular-indicial & $\begin{array}{l}\text { Indica um selo antigo, uma papel timbrado, garantia de procedência; } \\
\text { Tradição, herança, confiança, conhecimento; }\end{array}$ \\
\hline $\begin{array}{l}\text { Convencional- } \\
\text { simbólico }\end{array}$ & $\begin{array}{l}\text { Evoca uma harmonia clássica, uma distinção especial; } \\
\text { Beleza clássica, sofisticação, elegância, equilíbrio, superioridade. }\end{array}$ \\
\hline
\end{tabular}

Fonte: desenvolvido pelos autores

\subsubsection{O componente simbólico}

O símbolo da Hermès foi desenvolvido sobre a obra de 1830-1840, chamada "Le Duc Attelét», feita pelo artista Alfred de Dreux (ver figura 1B, acima). O desenho foi comprado por Emile Hermès, então no comando da empresa, e passou a fazer parte do logotipo entre 19431944. Segundo Ménéhould de Bazelaire, diretora do Hermès Cultural Heritage, a silhueta do

\footnotetext{
4 “O cavalariço à espera”, em tradução livre para o português.
} 
cavalariço esperando o(a) nobre patrão/patroa chegar, foi escolhida por sua capacidade de representar o tempo: passado - Paris aristocrática, época da fundação da companhia -, presente obra adquirida nos tempos da $2^{\mathrm{a}}$ Guerra Mundial, de grandes desafios -, e futuro - na expectativa da chegada do nobre que irá dirigir a carruagem $\left(\right.$ HERMÈS $\left.^{5}\right)$.

Quadro 4 : Análise semiótica do componente simbólico do logotipo Hermès

\begin{tabular}{|l|l|}
\hline Qualitativo-icônico & $\begin{array}{l}\text { Cavalos, carruagem e serviçal em silhueta. Ar livre, sol, situação estática; } \\
\text { Natureza, liberdade, ordem; }\end{array}$ \\
\hline Singular-indicial & $\begin{array}{l}\text { Indica um tempo de espera e uma aventura próxima (serviçal e cuidando } \\
\text { da carruagem). Nobreza, paciência, cuidado, movimento, ação; } \\
\text { Indica a origem da marca, quando não existiam carros. } \\
\text { Tradição, aristocracia; }\end{array}$ \\
\hline $\begin{array}{l}\text { Convencional- } \\
\text { simbólico }\end{array}$ & $\begin{array}{l}\text { Evoca o tempo passado (Paris aristocrática), presente (serviçal na espera) } \\
\text { e futuro (o movimento, a corrida, a aventura que irá em breve começar); } \\
\text { Aristocracia, requinte, tradição, perenidade da marca }\end{array}$ \\
\hline
\end{tabular}

Fonte: desenvolvido pelos autores

\subsubsection{Elemento cromático}

Dentre os elementos visuais que manifestam a marca, a cor é considerada primordial por vários estudiosos. A cor permeia a identidade marcária nos seus vários pontos de contato e as empresas podem fazer dela o principal elemento de sua identidade, ao utilizá-la consistentemente (SCHMITT; SIMONSON, 2002). Segundo Lindstrom (2005: 47), a cor é o "mais visível primeiro ponto de comunicação" das marcas.

O laranja queimado foi adotado como cor oficial da Hermès na década de 60, segundo a Vogue francesa ${ }^{6}$, quando a marca quebrou um padrão de estilo ocidental e se voltou para o Oriente, onde a cor significa serenidade, sabedoria e alegria de viver juntos. Desde então, é o tom cromático identificador e distintivo da Hermès, fundamental para proporcionar jovialidade e inovação à identidade marcária, carregada por elementos expressivos tradicionais, capazes de gerar efeitos de natureza mais fria e distante (aristocrática, imponente, superioridade, tradição, imortalidade, etc.).

\footnotetext{
${ }^{5}$ Depoimento em vídeo no site da empresa

${ }^{6}$ Em muitos blogs de moda e de branding, fala-se que escolha do laranja ocorreu ao acaso, em 1940, quando as embalagens de cor bege acabaram e foram substituídas pela única opção disponível durante a $2^{\mathrm{a}}$ Guerra Mundial. Porém, essa informação não foi encontrada no site oficial da marca, nem em jornais e revistas especializados.
} 
Quadro 5 - Análise semiótica do componente cromático do logotipo Hermès

\begin{tabular}{|l|l|}
\hline Qualitativo-icônico & $\begin{array}{l}\text { Cor secundária (vermelho + amarelo na síntese subtrativa); } \\
\text { Excitação, atividade, energia, calor, sol, descontração, alegria. } \\
\text { Atrai o olhar, chama a atenção: proximidade, intensidade. }\end{array}$ \\
\hline Singular-indicial & $\begin{array}{l}\text { Usada inicialmente nas embalagens, indica e diferencia hoje a Hermès } \\
\text { (única marca laranja na categoria luxo). Distinção, poder aquisitivo. }\end{array}$ \\
\hline $\begin{array}{l}\text { Convencional- } \\
\text { simbólico }\end{array}$ & $\begin{array}{l}\text { Cor exótica, alegre. Fruta originária da İndia. Inusitada e exclusiva, } \\
\text { pertinente para o luxo. No budismo, significa transformação, iluminação . }\end{array}$ \\
\hline
\end{tabular}

Fonte: desenvolvido pelos autores

\section{ANÁLISE SEMIÓTICA DE ELEMENTOS DO MARKETING MIX}

Foram selecionados três anúncios para a realização da análise semiótica baseada na Teoria Geral dos Signos de Peirce, considerando as três camadas dos signos, equivalentes aos três níveis distintos de percepção. O outono e o inverno, assim como a transição entre as duas estações climáticas, foram o tema dos anúncios impressos da marca (campanha global outono/inverno de 2012).

Fig. 2 - Peça impressa ${ }^{\circ} 1$

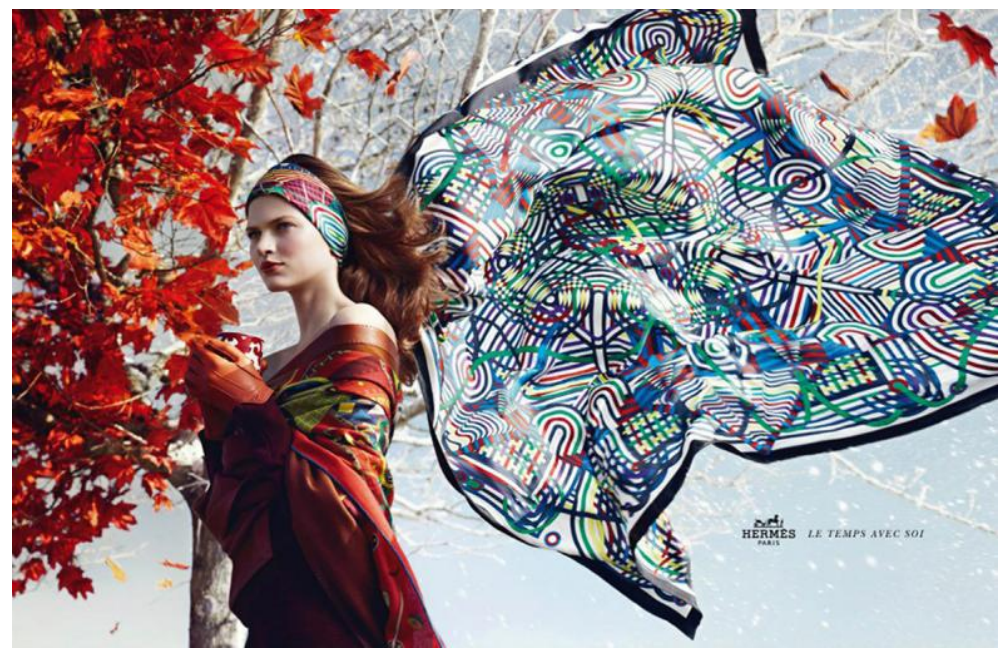

Fonte: página oficial da Hermès, no Pinterest (rede social de compartilhamento de imagens)

\subsubsection{Análise da peça $n^{o}$ 1: nível qualitativo- icônico}


$\mathrm{Na}$ dimensão textual, o anúncio apresenta, no canto direito, apenas o logo da marca com a assinatura da campanha "Le temps avec soi", em francês. Também foi realizada a versão do anúncio com o texto em inglês: "Time on your side".

$\mathrm{Na}$ dimensão visual, no primeiro plano, o anúncio apresenta uma moça com um lenço esvoaçante, amarrando seus cabelos. Esse acessório possui uma estampa gráfica com as cores verde, azul, vermelho e preto. A personagem olha o horizonte e segura com as mãos, protegidas por luvas laranjas, um objeto que parece ser uma caneca; e ao seu lado/fundo, uma árvore com folhas laranjas e uma parte esbranquiçada. Folhas e flocos de neve voam ao vento.

\subsubsection{Análise da peça n $n^{o}$ 1: nível singular-indicial}

A moça, que olha o horizonte, parece estar esperando por algo. Como a campanha é de outono e inverno, a luva nas mãos e a caneca indicam a necessidade de se aquecer. Portanto, a espera pode ser pelo inverno, anunciado pela parte desfolhada da árvore e pelos flocos de neve atrás do lenço, que ao ser levado pelo vento forma o desenho de asas de borboleta.

O lenço parece separar o primeiro plano (que é colorido pela vestimentas da moça e pelas folhas alaranjadas e que parecem representar o outono, época caracterizada pelo efeito de desfolhagem das árvores, e que é simultaneamente marcado por temperaturas quentes e frias), do segundo plano (o fundo que parece representar o inverno, por mostrar galhos esbranquiçados possivelmente pela neve e já sem as folhas.

\subsubsection{Análise da peça $n^{o}$ 1: nível convencional-simbólico}

Folhas e flocos de neve voam ao vento, anunciando a transição para um novo tempo, que não se refere apenas à mudança climática do outono para o inverno, mas também para uma nova época para marca de luxo, que vem traçando estratégias para resgatar seu core business. Isso é enfatizado pelo desenho das asas da borboleta (que o vento provocou com o lenço). A borboleta, em diversas culturas, simboliza renascimento e imortalidade. É possível fazer um paralelo entre a imortalidade com a tradição da marca francesa e entre o renascimento com a reação perante a crise econômica iniciada em 2008 e que ainda assola os países europeus. 
O lenço, tão importante para esta composição/representação, é uma dos acessórios mais vendidos pela marca, por ser um item da categoria acessível, assim como as luvas, e que desempenha um papel fundamental para as metas de vendas da empresa.

Fig. 3 - Peça impressa ${ }^{\circ} 2$

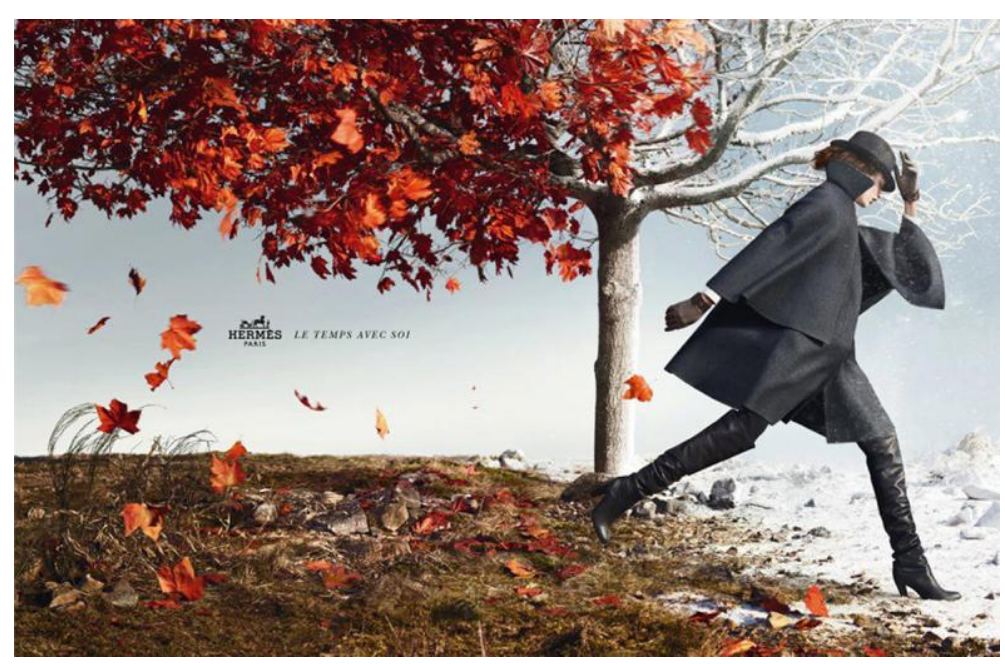

Fonte: página oficial da Hermès, no Pinterest (rede social de compartilhamento de imagens)

\subsubsection{Análise da peça ${ }^{\circ}$ 2: nível qualitativo- icônico}

Na dimensão textual, apenas a assinatura da campanha: "Le temps avec soi", e o logo da marca. Neste anúncio, a assinatura não se encontra no canto direito, mas exatamente embaixo da parte da árvore com a folhagem alaranjada, ao meio de folhas voando. Uma moça de vestes sóbrias com tons de cinza, preto e marrom, incluindo as botas e luvas, se desloca para o lado oposto ao da marca, tocando no chapéu com sua mão direita, e com a maior parte de seu corpo na parte do anúncio onde a árvore já está coberta pela neve, assim como o chão, que no pedaço onde está o pé esquerdo da personagem ainda é marrom esverdeado, formado por grama, arbustos e pedregulhos.

\subsubsection{Análise da peça $n^{\circ}$ 2: nível singular-indicial}

A parte da árvore e o chão esbranquiçados, no qual está a maior parte do corpo da personagem, estão cobertos por neve, o que justifica as vestimentas pesadas de inverno, cujo vento frio leva as folhas do outono para a direção contrária à qual a moça está se direcionando, 
o que pode indicar que o inverno está se instalando. A parte da árvore ainda com folhas predomina no anúncio, evidenciando que ainda é outono, que vai chegando ao fim. O logo da marca está posicionado sobre uma área na qual parece ter existido uma fogueira.

\subsubsection{Análise da peça $n^{\circ} 2$ : nível convencional-simbólico}

Claro que seria mais cômodo que a moça ficasse na parte do outono, mas as vestes da Hermès a preparam para enfrentar o inverno. Daí a marca estar sobre o local no qual supostamente existiu uma fogueira, indicando que a Hermès, assim como o fogo, produz o calor necessário para que se enfrente o frio. Portanto a personagem não foge da marca, caminhando ao lado oposto a ela, e sim, segue seu caminho graças ao que a marca lhe proporcionou, e que vai além à proteção física e conforto, mas também autossuficiência e confiança, atributos fundamentais para o cenário pós-moderno no qual todos parecem estar em fuga. 
Fig. 4 - Peça impressa no 3

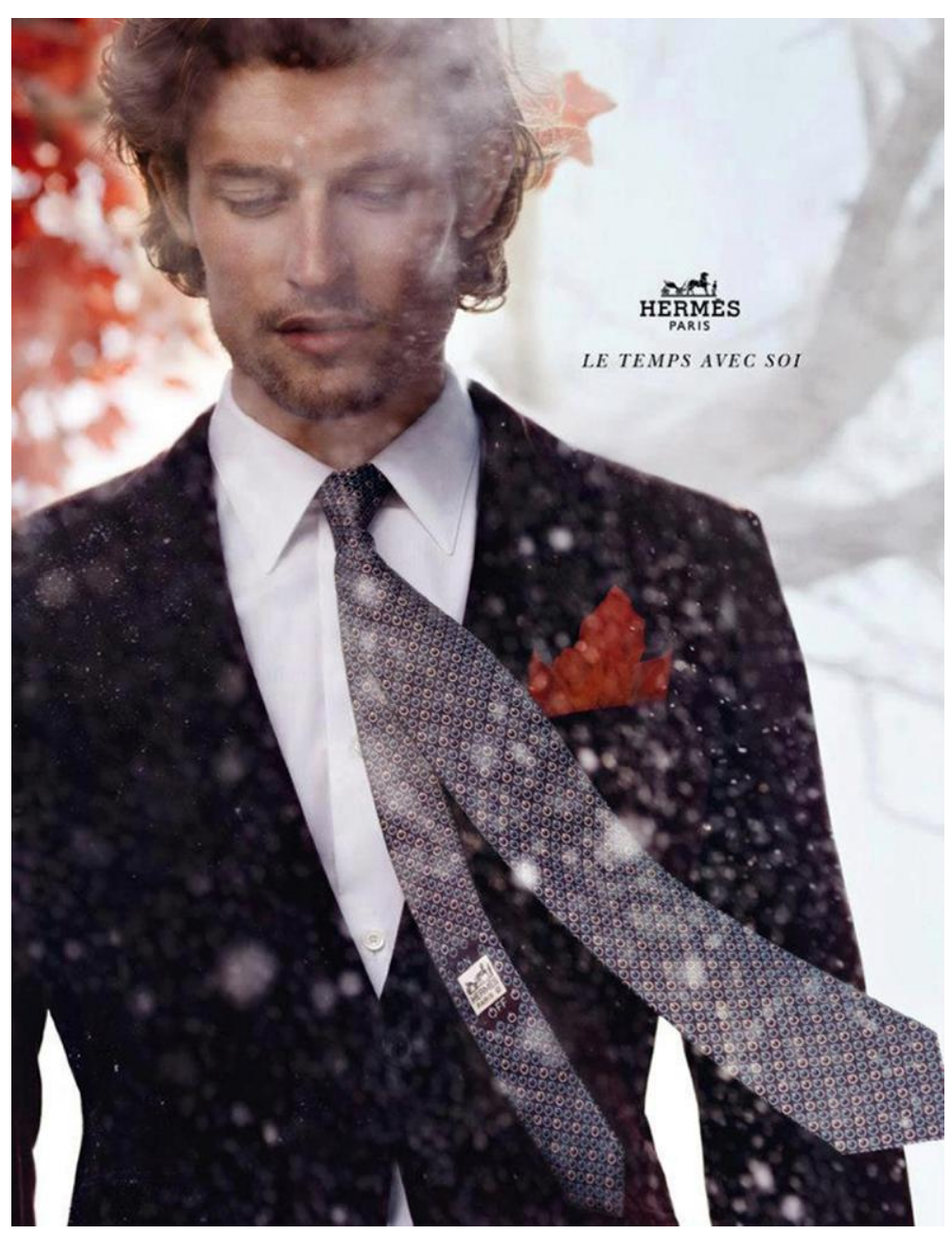

Fonte: página oficial da Hermès, no Pinterest (rede social de compartilhamento de imagens)

\subsubsection{Análise da peça nº 3: nível qualitativo- icônico}

$\mathrm{O}$ anúncio traz em primeiro plano um rapaz de terno preto, com camisa branca e gravata virada pelo vento e que por isso, está com uma etiqueta à mostra. No canto superior direito da página, o logo da marca, como se estivesse sobre o ombro do rapaz. No fundo a imagem da mesma árvore dos anúncios anteriores levemente embaçada, com uma parte com folhas alaranjadas e a outra com galhos vazios. Em primeiro plano, pontos esbranquiçados na frente do rapaz que caminha.

\subsubsection{Análise da peça n ${ }^{o}$ 3: nível singular-indicial}


O rapaz está caminhando para frente, no sentido do leitor, deixando para traz a mesma árvore que representa a transição do outono para o inverno. À sua frente: neve. No entanto, o rapaz mantém uma expressão serena e até apática frente à temperatura térmica capaz de provocá-la. No bolso de seu paletó, uma folha de cor laranja, que provavelmente se desprendeu da árvore ao fundo.

\subsubsection{Análise da peça nº3: nível convencional-simbólico}

Assim como nos anúncios anteriores, nos quais os personagens parecem esperar o inverno sem medo ou sofrimento, esta propaganda traz a mesma mensagem: a de se ter o tempo a seu favor. É a marca novamente que proporciona a segurança para se enfrentar a neve de frente. Tempo aqui, significando uma estação climática, mas também remetendo ao tempo de existência da marca, que sempre se renovou sem perder a tradição, que é simbolizada pela folha laranja do outono que permaneceu no bolso: o tempo muda, mas há sempre algo que permanece. Um discurso muito pertinente para a estratégia de se resgatar o core business da marca, o que justifica a seleção de uma folhagem de tom laranja, cor muito marcante na trajetória da Hermès. A tradição também está muito bem simbolizada no terno, um item clássico (atemporal).

\subsection{A árvore}

A árvore em questão, presente em todos os anúncios, pertence à família Platanaceae, mais especificamente do gênero Platanus. É uma árvore comumente utilizada para fins ornamentais, e como tal, possui função paisagística, de embelezamento do ambiente. Ademais, seu caráter híbrido entre espécies europeias e americanas, pode sinalizar o caráter difundido e adaptado da marca às diversas culturas atuais. Por fim, e principalmente, possui como características marcantes: crescimento rápido, que pode representar o sucesso da marca; resistência a podas, que pode simbolizar a crise global; e longevidade (algumas espécies duram até 2000 anos), simbolizando a tradição (MARCHIORI,1997).

\section{CAMPANHA HERMÈS E OS RITUAIS DE CONSUMO}


Outro aspecto assaz importante para um entendimento complementar dos apontamentos trazidos à luz da semiótica peirceana refere-se aos rituais de consumo e suas implicações na transferência de significado, apresentados por McCracken (2003).

Nesse sentido, há, segundo o autor, três lugares-chave a partir dos quais o significado faz sua trajetória, a saber: o mundo culturalmente constituído, os bens de consumo e, por fim, os próprios consumidores.

Fig. 5A-5B - O processo de transferência de significado
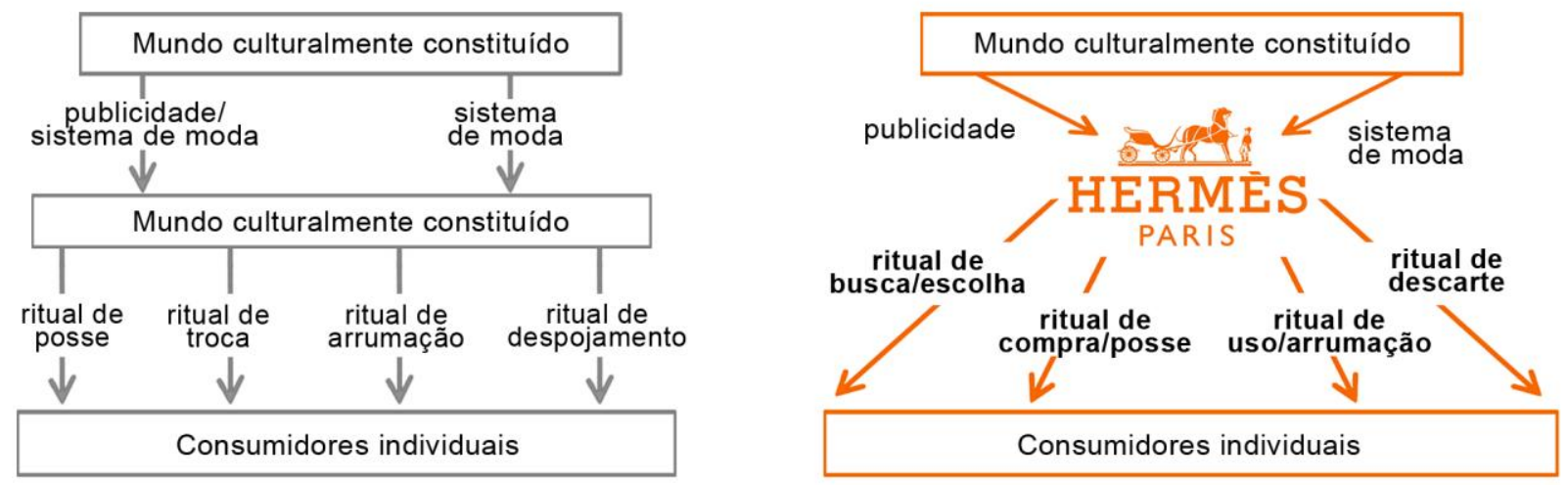

Fonte: 5A - McCracken, 2003. 5B- desenvolvido pelos autores, a partir e modelo de McCracken, 2003

Como se vê na representação acima (Figura 5A), em um primeiro momento, o significado reside no mundo culturalmente constituído. É nele em que os fenômenos se apresentam aos indivíduos, imersos em uma dada cultura que determinará como tais fenômenos serão vistos e, consequentemente, qual será o comportamento esperado na esfera da ação, aquilo que McCracken chama de lentes e plano de ação presentes em um mundo forjado pela cultura (2003: 101). Nesse sentido, podemos contextualizar o cenário atual a partir das considerações trazidas por Lipovetsky (2004), a respeito do mundo guiado pela evolução rápida e constante, que torna imperativo, por parte das empresas, considerar tais aspectos e inseri-los na lógica da inovação e da rentabilidade, fatores que incidem diretamente na esfera da moda, considerada neste trabalho.

Ainda no primeiro estágio, do mundo culturalmente constituído, dois importantes instrumentos operam para determinar a trajetória do significado em direção aos bens de consumo: a publicidade e a moda. Não cabe neste trabalho detalharmos o funcionamento de 
cada um deles (uma vez que o foco está em apresentar o último estágio dessa cadeia, ou seja, identificando de que forma o significado é transferido para os consumidores, a partir dos distintos rituais de consumo aqui propostos), mas, de forma geral, é valido mencionarmos que tanto a publicidade como a moda atuam de forma a selecionar determinadas características presentes no mundo culturalmente constituído e torná-las presentes nos bens sobre os quais eles operam, dotando-os de significado desejável a partir de um dado contexto cultural e mercadológico.

Uma vez situados nos bens é que se torna viável, por parte dos consumidores, a apropriação ou não dos significados em circulação. É justamente neste ponto que os quatro rituais de consumo propostos por McCracken se fazem presentes: ritual de troca, de posse, de arrumação e de despojamento (2003: 115).

É preciso ressaltar, contudo, que os rituais nem sempre aparecem de forma evidente ou equipresente. Ao contrário, muitas vezes, o que se nota em determinadas campanhas publicitárias é a preponderância de certos rituais em detrimento de outros. Posto isso, para fins de análise e uma melhor compreensão da campanha, identificamos 3 rituais que estariam subentendidos (ritual de despojamento, de troca e de arrumação) e um ritual (de posse) que se apresenta com maior destaque nas peças publicitárias aqui estudadas. Além disso, destacamos também como os bens da marca Hermès se situam na dinâmica do processo de transferência de significado, tal como exposto na figura 5B (ver acima).

\subsection{Rituais Implícitos}

\subsubsection{Rituais implícitos: DEPOJAMENTO}

Ao anunciar a nova coleção de inverno da Hermès, a marca pressupõe que, antes de tudo, o consumidor estabeleça uma nova relação com os produtos que ele já possui, ou seja, que eles sejam descartados, ou, na melhor das hipóteses, tenham sua importância e preferência diminuídas frente aos novos anseios advindos da campanha. Em uma abordagem prática, podemos citar como o processo de "renovação do armário".

\subsubsection{Rituais implícitos: TROCA}


A forma que consideramos mais adequada aqui foi a de entender o ritual de troca como sendo o processo de compra dos produtos Hermès anunciados, muito embora McCracken faça uma abordagem desse ritual a partir dos eventos nos quais há a troca de presentes, em ocasiões como o Natal, por exemplo (2003: 115). Ademais, é nessa etapa, ao realizar a busca e a compra dos produtos, que o receptor dos produtos Hermès (consumidores) deseja ver transferidos os valores expressos nos produtos (elegância, tradição e refinamento) para si próprio, ou seja, é a finalidade da compra que concretiza o anseio pelas características atribuídas à marca.

\subsubsection{Rituais implícitos: ARRUMAÇ̃̃O}

Neste estágio, espera-se que as propriedades embutidas nas peças de vestuário sejam ressaltadas, através de uma correta combinação das peças (no caso, da marca Hermès). Além disso, é aqui que o indivíduo ganha autoestima e confiança, estando devidamente preparado para sua "incursão" no ambiente em que vive, sedimentando os estágios que trarão em evidência o ritual explícito de posse.

\subsection{Rituais explícitos}

\subsubsection{Rituais explícitos: POSSE}

É neste ritual que os elementos que caracterizam a marca (cor laranja) e a definem como sendo uma marca de luxo, tradicional e elegante, e cuja raiz se deu na venda de artigos para montaria (selas, baús, etc.), se unem à representação dada na campanha publicitária, através da presença da cor alaranjada das folhas que caem no outono, do cenário não-edificado, que remete ao período de sua origem (século XIX), dos artigos em couro e da modelo elegantemente vestida, que, aqui sim, faz uso dos produtos da marca e que caminha com segurança para a nova estação que se apresenta, o inverno. Destarte, nas palavras de McCracken, "através de seus rituais de posse, os indivíduos transferem o significado dos bens para suas vidas" (2003: 116).

Por fim, é importante salientar ainda a relação existente entre a representação da modelo na campanha, que veste a marca de luxo, e os aspectos cultuais presentes no século XIX, como o passeio público e a exposição social, que se constituíam como um momento de aparição social 
para a aristocracia. Era o "sair de casa", que marcava a saída do privado para o público, um ritual no qual a indumentária era um dos principais aspectos da distinção social. Assim, destacam-se aqui, alguns elementos/conceitos que se fazem notáveis tanto no século XIX como na campanha da marca, como: natureza, ar livre, exibição, liberdade, aristocracia e distinção social.

\section{CONSIDERAÇÕES FINAIS}

A análise semiótica das expressividades da Hermès evidencia que a marca explora fortemente os efeitos de sentidos ligados à tradição, à distinção social, à sofisticação e excelência de qualidade do luxo feito à mão, nos elementos do identity mix (o logotipo e as embalagens, inclusive, permanecem inalterados há décadas) e marketing mix. Os aspectos de proximidade, calor e modernidade, para compensar uma eventual impressão de frieza, envelhecimento e distância aristocrática, são gerados pela cor laranja, identificadora da marca.

Em sinergia e complementariedade, os elementos do marketing mix equilibram os efeitos de tradição, distinção e sofisticação com os efeitos de criatividade e moda, movimento e encantamento, transformação e inovação. Como exemplos, tem-se o evidente resgate do core business da empresa, enaltecendo seus produtos mais clássicos e também os mais "acessíveis", devido à atual crise na economia, e a referência à autoestima, confiança e poder que se obtém ao utilizar a marca Hermès (rituais de posse e uso).

Passado, presente e futuro são conceitos amplamente explorados nas potencialidades emocionais, funcionais e lógicas de efeitos de sentido, reforçando as associações de imortalidade, perenidade, eternidade - valores fundamentais para as marcas do segmento em questão, ainda mais no cenário pós-moderno.

As expressividades da Hermès estão totalmente integradas com as estratégias da marca, e deste modo ajudam a proteger a empresa em tempos de incerteza financeira mundial e de mutação da lógica do luxo. Elas também fortalecem o vínculo com seus públicos, os intérpretes das construções sígnicas aqui analisadas, indivíduos que valorizam e buscam "tomar para si”" os efeitos de sentido gerados, por meio do consumo da marca Hermès.

\section{REFERÊNCIAS BIBLIOGRÁFICAS}


Hermès: expressões da marca e rituais de consumo

de Flávia Igliori Gonsales, Diogo Kawano e Janiene Santos

ALLEN, T., SIMMONS, J. "Visual and verbal identity", in Brands and Branding (The Economist Series). CLIFTON, R., SIMMONS (eds), J. London, Bloomberg Press, 2004.

CIRLOT, J. E. A dictionary of symbols. London, Routledge, 1971.

EXAME. "Como a Hermès luta para não cair nas garras da Louis Vuitton”, in Exame.com, São Paulo, 16/12/2011. Disponível em: < http://exame.abril.com.br/negocios/empresas/noticias/como-a-hermes-luta-para-nao-cairnas-garras-da-louis-vuitton >. Acesso em: 10/12/2012.

GOBÉ, M. Emocional branding. New York, Allworth Press, 2009.

HELLER, E. Psicología del color: como actúan los colores sobre los sentimentos y la razón. Barcelona, Gustavo Gili, 2008.

HÈRMES, site da empresa. Disponível em: <http://hermes.com> Acesso em: 10/12/2012.

HÈRMES, página oficial no Pinterest. Disponível em: < http://pinterest.com/hermesofficial/> Acesso em: 10/12/2012.

JORDÃO, C. “'O desembarque da Hermès no Brasil”, in Isto É, São Paulo, 29/08/2009. Disponível em: <http://www.istoe.com.br/reportagens/17028_o+desembarque+da+hermes+no+brasil>. Acesso em: 10/12/2012.

LENCASTRE, P \& CÔRTE-REAL, A. "Um triângulo da marca para evitar a branding myopia: contribuição semiótica para um modelo integrado de compreensão da marca" in Revista Organicom, vol. 4, n 7, São Paulo, 2007, p. 99-113.

LINDSTROM, M. Brand sense: build powerful brands though touch, taste, smell, sight, and sound. New York, Free Press, 2005.

LIPOVETSKY, Gilles. Os tempos hipermodernos. São Paulo, Barcarolla, 2004.

LIPOVETSKY, G. \& ROUX, E. O luxo eterno: da idade do sagrado ao tempo das marcas. São Paulo, Companhia das Letras, 2005.

MARCHIORI, J. N. C. Dendrologia das angiospermas: das magnoliáceas às flacurtiáceas. Santa Maria, Ed. UFSM, 1997.

MCCRACKEN, G. Cultura e Consumo: novas abordagens ao caráter simbólico dos bens e das atividades de consumo. Rio de Janeiro, Mauad, 2003.

MCCRACKEN, G. Cultura e Consumo II: mercados, significados e gerenciamento de marcas Rio de Janeiro, Mauad, 2012.

MILETSKY, J.; SMITH, G. Perspectives on Branding. USA,Course Technology PTR, 2009. 
Hermès: expressões da marca e rituais de consumo

de Flávia Igliori Gonsales, Diogo Kawano e Janiene Santos

MILLWARD BROWN. "2012 BrandZ Top 100: most valuable global brands”. Disponível em: < http://www.millwardbrown.com/brandz/Top_100_Global_Brands.aspx >. Acesso em: 10/12/2012.

PEIRCE, C. S. Semiótica. São Paulo, Perspectiva, 1995.

PEREZ, C. Signos da marca: expressividade e sensorialidade. São Paulo, Thomson, 2004.

PEREZ, C.; BAIRON, S. "Imagem de marca: a recepção sígnica a partir do interpretante peirceano", in Animus- revista interamericana de comunicação mediática, vol. 15, 2009 - 1. Disponível em: <http://w3.ufsm.br/animus/animus_2009_art08.html>. Acesso em 10/11/2011.

ROGENER, S., POOL, A., \& PACKHAUSER, U. Branding with type: How type sells. Califórnia, Adobe Press, 1995.

SANTAELLA, L. A teoria geral dos signos. São Paulo, Thomson, 2000. . Semiótica Aplicada. São Paulo, Thomson, 2003.

SCHMITT, B.; SIMONSON, A. A estética do marketing: como criar e administrar sua marca, imagem e identidade. São Paulo, Nobel, 2002.

THE WALL STREET JOURNAL. "The Battle for Hermès”, New York, 25/08/2011. Disponível em: <http://online.wsj.com/article/SB10001424053111903596904576517151602728260.html Acesso em: 10/12/2012.

VOGUE FRANCE. "Hermes, the famous boutique luxury silk scarf". Disponível em: < http://www.vogue.fr/thevoguelist/articles/hermes-la-boutique-de-luxe-au-celebre-carrede-soie/8860\#> Acesso em: 10/12/2012.

Artigo recebido: 05/2012

Artigo aprovado: 06/2012 